LABORATORY EVALUATION OF BENGKULU ISOLATES OF

\title{
Beauveria bassiana AND Metarhizium anisopliae AGAINST COFFEE BERRY BORER, Hyphotenemus hampei, USING SPRAYING METHOD
}

\author{
Dwinardi Apriyanto \& Nadrawati \\ Department of Plant Protection, University of Bengkulu, Indonesia \\ Jl. Wr. Supratman Bengkulu 38371 \\ E-mail:kang_dwi@unib.ac.id
}

\begin{abstract}
Laboratory evaluation of local isolates of Beauveria bassiana and Metarhizium anisopliae against coffee berry borer, Hyphotenemus hampei, using spraying method. Beauveria bassiana Bals (Vuillemin) and Metarhizium anisopliae (Metschnikoff) Sorokin are two species of fungi that have been studied widely and used as biological control of various insect pests, including coffee berry borer (CBB), Hyphotenemus hampei Ferrari. Laboratory studies were done in June - July 2017, to evaluate local isolates of both fungi species against $\mathrm{CBB}$, the most destructive insect pest of coffee worldwide, including in Indonesia. B. bassiana was isolated from dead sweet potato weevil (Cylas formicarius) and green stink bug (Nezara viridula), and from soil. M. anisopliae was isolated from soil. The pure cultures of the fungi were mass-cultured on corn based media. The conidia harvested from 4 week colonies was hand sprayed directly upon CBB adults (females) and damaged coffee berry at the concentration of $10^{9} / \mathrm{mL}$. In additions, the conidia of B. bassiana isolated from C. formicarius alone was diluted to $10^{6}-10^{9} / \mathrm{mL}$ and applied to damaged coffee berry. The results showed that when the conidia were applied directly upon the insects, the mortality of beetle were higher in B. bassiana than in M. anisopliae treatments. Pooled data indicated that $B$. bassiana isolated from death insects were significantly caused higher mortality than that and M. anisopliae isolated from soil. Beetle mortality was 76.7 and $80.0 \%$ for B. basiana, and 60.3 and $60 \%$ for $M$. ansopliae treatments. Application upon damage coffee berry indicated much lower mortality of pupae and adults. Application of higher concentration upon damaged coffee berry resulted higher mortality, but data are not consistent. The mortality of CBB larvae was much less and negligible even at the highest conidia concentration. This study revealed that local isolate of B. bassiana was more effective than M. anisopliae. Spaying method both directly to CBB adult and to damaged coffee berries may be used as an alternative for evaluating small number of fungus isolates, but it should be preceded with viability and germination tests.
\end{abstract}

Key words: adult and pupae mortality, biological control, conidia concentration, damaged of coffee berry, dead of Cylas formicarius, dead of Nezara viridula

\section{INTRODUCTION}

Coffee berry borer (CBB), Hypothenemus hampei Ferrari, is considered as the most destructive insect pest of coffee worldwide (Damon, 2000; Vega, 2004; Benavides et al., 2012; Jaramillo et al., 2006; Jaramillo et al., 2011; Aristizabal et al., 2012; Vega et al., 2015), including in many coffee growing areas of Indonesia (Wiryadiputra, 2012; Sitanggang et al., 2017). Yield loss by CBB varies from low to very high. Vega (2004) estimated the global annual economic loss caused by this pest being above $\$ 500$ million. Estimated annual revenue loss for Indonesian coffee growers averaged $\$ 6.7$ million (Wiryadiputra et al., 2008). This insect pest remains problem for the small holder coffee plantations in Indonesia and it is even worse in Bengkulu, where coffee berries are always present yearlong due to overlapping coffee berries development stage (i.e. multiple blooming periods). In addition, farmers in Bengkulu practiced traditional dry berry processing, where harvested coffee berries are dried on the ground, even in the field, facilitating CBB to fly back and reinfest the remaining coffee berries in the field. Overlapping fruit development does not allow time line harvesting that does not left many berries in field. Collection of fallen and removal of left over ripe and dry berries reduced levels of CBB infestation by $>64 \%$ during a coffee production cycle. The phenomena of CBB reinfestation from processing station to the field had been reported from study in Colombia, which may reach as high as $75 \%$ of field population (Benavides et al., 2012).

Many coffee producing countries, ones relay on insecticide uses (Damon, 2000; Baker et al., 2002; Aristizabal et al., 2012; Infante, 2018) with increasing 
rate, even though growers realized the consequences of the side effects to the target and non-target insects as well as to the environment and human health. However, synthetic insecticides are increasingly replaced with other means of measures as the growers are more educated about negative side effects of the chemicals to the environment and human health, and consumers demand more healthy foods and goods.

It has been well realized that pest species evolves fast in response to insecticide applications. Sparks \& Nauen (2014) reviewed that 586 pest species has developed resistance to one or more insecticides and 5 species resistance to resistance trait of genetically modified plants. Cases of increased resistance of CBB have been reported in some countries (Brun \& Suckling, 1992; Brun et al., 1989; Brun et al., 1995; Infante, 2018). Therefore, it is desirable that more ecologically-sound technologies be practiced to combat the pest. Studies to find such technologies are numerous, including the use of natural enemies (Perez-Lachaud et al., 2002; Jaramillo et al., 2006; Pérez et al., 2015; Mascarin et al., 2016; Patocka, 2016), botanical insecticide (Celestino et al., 2016), and mass trapping CBB adult (Dufour \& Fre'rot, 2008; Wiryadiputra et al., 2008).

The use of natural enemies to control CBB has been reported worldwide in many publications (PerezLachaud et al., 2002; Jaramillo et al., 2006; Patocka, 2016), with variably results. Beauveria bassiana Bals (Vuillemin) is the most frequently reported as the most effective fungus, as mycoinsecticide among others, including Metarhizium anisopliae (Metschnikoff) Sorokin, the second most popular fungus species for biological control of many insect pests (Jaramillo et al., 2006). The mycosis was reported on CBB in Mexico in field conditions, which overall higher on coffee berries samples taken from $B$. bassiana treated trees than that on ones treated with $M$. anisopliae, though it varied among strains between elevations, and to some extent being higher in locations of higher elevation (Rosa et al., 2000).

Beauveria bassiana spore was reported to be transported from one attacked coffee berry to others, reducing the fecundity of CBB (Dembilio et al., 2010). This fungus also produces a number of secondary metabolites that effective not only to insect which has causes long coevolution in fungus-insect interaction, but also poses potency as medicine (Patocka, 2016).

In many screening method researchers usually used dipping method, the beetles were dipped into conidia suspension for two minutes or so (Posada \& Vega, 2005; Benavides et al., 2012; Balakrishnan \& Naik, 2014; Belay \& Tenkegna, 2017) for the sake of simplicity. This method is more efficient for screening large numbers of fungus isolates. A laboratory study was conducted to evaluate three isolates of $B$. bassiana and two isolates of $M$. anisopliae, using spraying method, the conidia suspension was sprayed upon the beetles or upon damaged (bored) coffee berries. This method is more realistic so as to mimic field application. The objective was to evaluate the effectiveness of local isolate isolated from dead hosts and soil in causing mortality on CCB. Here we reported the results of our works.

\section{MATERIALS AND METHODS}

Research Site. All of works, from isolation until conducting experiment, were performed at Laboratory of Biological Control, Department of Plant Protection Faculty of Agriculture University of Bengkulu in JuneJuly 2017.

Fungi Isolation and Culturing. B. bassiana was isolated from death insects (Cylas formicarius and Nezara viridula), whereas M. anisopliae was isolated from soil taken from farmer's coffee garden and from food crops field, in Kepahyang Municipilicity. For simplicity, all isolates are abbreviated here, following the sequence above, as Cf-Bb, Nv-Bb, sc-Ma, and sfc-Ma.

Pure cultures of all isolates were established in potato dextrose agar (PDA). Each fungus isolates from pure culture was further mass-cultured on ground cornbased media. Ground corn ( $\pm 3 \mathrm{~mm}$ diameter) was purchased in local market. The media was rinsed and cocked in aluminium jar for 5 minutes, put in $0.5 \mathrm{~kg}$ plastic bag, $100 \mathrm{~g}$ per bag and sterilized in autoclave for 30 minutes. The inoculation of $B$. bassiana spore of all isolates that were prepared from pure culture was done inside laminar air flow. The cultures then were kept in tray in room temperature $\left(28{ }^{\circ} \mathrm{C}\right.$ and fluctuating $\mathrm{RH}$ from $70-80 \%$ ) until used for application.

Pathogenicity Test. Pathogenicity test was conducted to evaluate the performance of aforementioned four fungi isolates in causing mortality to CBB. Conidia of all isolates were test germinated before used for laboratory trial and all germinate above $90 \%$. The trial was conducted in air-conditioned room, maintained at $25^{\circ} \mathrm{C}$, RH $75 \%$.

An experiment was set with petri-dishes $(15 \mathrm{~cm}$ diameter) arena, each consisting of $30 \mathrm{CBBs}$ (females). The treatments (B. basiana isolates) were replicated three times. CBBs were collected from Robusta coffee with "Brocap trap" baited with attractant, "Hyphotan" 
(ethanol : methanol [1:1]) (ICCRI, Jember). The conidia suspension of each isolate at the concentration of $10^{9} /$ $\mathrm{mL}$ was prepared from 4 weeks old fungus culture, added with $0.1 \%$ Tween 80 (Brataco Chemica, Bandung). The conidia suspension was sprayed directly upon CBBs with $500 \mathrm{~mL}$ hand-sprayer in petri-dish arena lined with sterilized tissue paper. The treated CBBs were provided with fresh green-mature coffee berries which had been punched with sterilized needle to provide entrance for the beetles. The beetles and coffee bean used in this test were surface sterilized by washing them in $0.5 \%$ sodium hypochlorite solution, followed by rinsing in sterile water, i.e. followed method of Posada \& Vega (2005). The effects of conidia treatments of all fungi isolates was determined by counting of infected and died CBB.

The observation of infected beetles (died and showed infection symptom) was performed every day until day 10. Dead CBBs that have not showed infection yet were kept in sterile petri dishes (diameter $19 \mathrm{~cm}$ ) containing $10 \mathrm{~mL}$ PDA to allow mycelia of the fungus emerge from the beetle surface. The daily infected CBBs were accumulated to day 10 and subjected to analysis of variance (ANOVA), followed with LSD using statistic software, Statistix 8 (Analytic Software, Talahase-Florida). The best isolate from this test was further tested in conidia concentration experiments.

Another pathogenicity tests were conducted to determine effectiveness of $B$. bassiana isolates against CBB inside damaged coffee berries. The coffee berries were obtained from farmer field in Kepahiang Municipality, Bengkulu. It is not uncommon that all stages of coffee berry (from blooming-young mature greenyellow-red berries) are all occurred at the same time whole year, and CBB infestation may start at even young berries (has not suitable for CBB feeding). In order to be more certain that the sampled damaged (bored) coffee berries contain $\mathrm{CBB}$ inside, we selected only green-yellow berries. We assumed that if boring female $\mathrm{CBB}$ continued to reproduced, there must be all stages of CBB (egg, larvae, pupae and imago) inside the damaged coffee berries. However, it was not possible to ascertain that all coffee berries sampled contain CBBs inside. It was also not possible to confirm that CBBs inside coffee berry samples were not free from $B$. bassiana natural infection, but from observation and fungus isolation performed before the experiments, revealed that natural infection of this fungus from the same location was very low, less than $1 \%$.

The experiment was conducted in similar room condition as before. In each experimental unite (a petri dish) we used 30 damage coffee berries. The conidia suspension of each isolate was sprayed upon greenyellow mature damaged coffee berries. Conidia suspension of $10^{9} / \mathrm{mL}$ was added with $0.1 \%$ Tween 80 or Pro Synergist (Leily Agrochemistry, China). The treatments were: 1) $\mathrm{Cf}-\mathrm{Bb}+$ Tween 80 ; 2) $\mathrm{Cf}-\mathrm{Bb}+$ Pro Syn.; 3) Nv-Bb+Tween 80; 4) Nv-Bb+Pro Syn. All treatments were replicated three times. Observation of affected CBB was performed by opening the coffee berry one by one and counting the number of egg, dead and/or infected larvae, pupae and adults at day 10 after treatment.

Cf-Bb Conidia Concentration Test. Cf-Bb isolate gave the best result in the previous test (see bellows), therefore it was continued to the next test to evaluate the effects of different conidia concentrations on CBB mortality. The test was conducted in similar procedure as above, the conidia applied upon damaged coffee berries, at concentrations of $1 \times 10^{6}, 1 \times 10^{7}, 1 \times 10^{8}$, and $1 \times 10^{9} / \mathrm{mL}$. All concentrations were added with Tween $800.1 \%$. Control treatment (water $+0.1 \%$ Tween 80 ) was included. Conidia suspension of each concentration was sprayed upon 10 damaged coffee berries as experimental unit. Each conidia concentration was replicated three times. The treated berries were put into plastic petri dishes (19 $\mathrm{cm}$ diameter), coffered with wrapping plastic punctured with a micro needle. Observations were performed at day 9 after treatment. All coffee berries used in the trial were opened (cut) one by one with a cutter and the beetles found were checked carefully. Live and dead larva, pupae and adult stages of CBB were recorded separately and mortality of each was determined. Data were analysed with ANOVA and followed with least significant different (LSD) test for means separation with Statstix 8.

\section{RESULTS AND DISCUSSION}

\section{Pathogenicity of Local Isolates of $B$. bassiana and} M. anisopliae. The difference between B. bassiana and $M$. anisopliae was apparent from the color of mycelia of both after the infected CCBs were transferred to petri dishes, white for the first fungus and grey for the second (Figure 1). The mortality of CBBs as a result of $B$. bassiana and $M$. anisopliae infection ranged $60-80 \%$. The differences of number and percentage of dead CBBs between treatments of $B$. bassiana isolated from dead insects and $M$. anisopliae taken from soil under coffee canopies were not significant (Table 1), but pooled data of each fungus species revealed that $B$. bassiana isolates from dead insects significantly caused higher mortality to CBBs 
than M. anisopliae taken from soil $(\mathrm{t}=2.94, \mathrm{df}=10, \mathrm{P}$ $=0.0149)$. This result is in accordance with finding by Rosa et al. (2000), that B. bassiana was more infective against $\mathrm{CBB}$ than $M$. anisopliae.

$\mathrm{Cf}-\mathrm{Bb}$ isolate was the most effective in causing $\mathrm{CBB}$ death. Even though the differences of means between $\mathrm{Cf}-\mathrm{Bb}, \mathrm{Nv}-\mathrm{Bb}$ and sc-Bb were not significant, $B$. bassiana isolate taken from $C$. formicarius resulted higher mortality than did isolate taken from $N$. viridula. These results might occur purely by chance alone. Results of B. bassiana screening by Rosa et al. (1997) also varied between isolates. They evaluated 18 isolates from three countries and resulted $\mathrm{CBB}$ mortality ranging from $20.1-100 \%$. It seems also logical to argue that in our finding, $\mathrm{Cf}-\mathrm{Bb}$ was more adapted to $\mathrm{CBB}$ because it was isolated from closer related host species, whereas $\mathrm{Nv}-\mathrm{Bb}$ was from more distant one. In many cases, entomopathogen isolates were more virulent to the same host as they were isolated or to closely related host species. However, there also some cases where the opposites also occurred, the isolates were more virulent to more distant host species (Feng et al., 1994). Regardless of the arguments, based on the result, we used isolate from $C$. formicarius $(\mathrm{Cf}-\mathrm{Bb})$ for further evaluation in the next test (i.e. conidia concentrations).

Our result is lower than that reported by Belay \& Tenkegna (2017), Rosa et al. (1997) and Posada \& Vega (2005) on B. bassiana, and of Balakrishnan \& Naik (2014) on M. anisopliae. The differences might indicate that our isolates are less effective as compared to the isolate they examined. However it is also plausible to argue that differences between our result and other researcher's might be attributed more to the different methods used rather than to the lower virulence of our isolates. We used spraying method, whereas they did dipping method, in which theoretically, the later provides higher chance of contact between conidia and CBB. We used spraying method so as to mimic real application in field, while the above researchers used for the sake of practical reason, simplicity and efficiency for screening large number of isolates, because the result much quicker (i.e. $\mathrm{LT}_{50}$ is much shorter) and less laborious.

In general, $\mathrm{Cf}-\mathrm{Bb}$ isolate applied upon damaged coffee berries caused higher CBB mortality than $\mathrm{Nv}-\mathrm{Bb}$ isolate (Figure 2). Tween 80 was used in conidia concentration tests. This result is consistent with the previous trial using CBB alone. Application of conidia upon damaged coffee berries gave much lower mortality than direct application upon CBB.

Effect of Conidia Concentration on CBB Mortality. Not all selected damaged coffee berries used in experiment contain $\mathrm{CBB}$; in fact, there were more that did not. However, the data obtained were able to show that CBB mortality was higher in coffee berries treated with higher conidia concentration (Table 2). Larval mortality (data are excluded) was very low in both tests

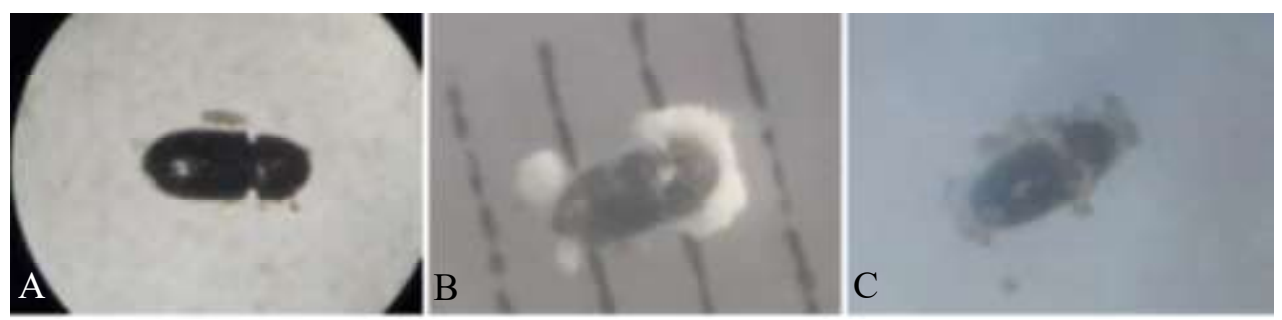

Figure 1. Coffee berry borer (CBB); (A) Healthy CBB, (B) infected by Beauveria bassiana, (C) infected by Metharhizium anisopliae.

Table 1. Means of numbers of adult CBB died and percent mortality from infection by fungus isolates

\begin{tabular}{ccc}
\hline Fungi isolates & Number of CBB died & \% mortality \\
\hline $\mathrm{Cf}-\mathrm{Bb}$ & $21.0 \pm 6.49 \mathrm{a}$ & $80.0 \pm 8.16 \mathrm{a}$ \\
$\mathrm{Nv}-\mathrm{Bb}$ & $24.0 \pm 2.45 \mathrm{ab}$ & $76.7 \pm 12.47 \mathrm{ab}$ \\
sc-Ma $^{1)}$ & $19.0 \pm 1.41 \mathrm{ab}$ & $63.3 \pm 4.71 \mathrm{ab}$ \\
sfc-Ma $^{2)}$ & $16.0 \pm 3.74 \mathrm{~b}$ & $60.0 \pm 8.16 \mathrm{~b}$ \\
Control (water) & $0 \mathrm{c}$ & $0 \mathrm{c}$ \\
\hline
\end{tabular}

1) The fungus was isolated from soil taken from coffee garden; ${ }^{2)}$ The fungus was isolated from soil taken from food-crop. Means followed by the same later in the same column do not differ significantly (LSD; $\alpha=0.05$ ). 
and this might be an indication of being less susceptible, or simply because they escaped from infection due to deeper position of the larvae inside the coffee seed. It would take longer time for conidia that germinate to reach the position of larvae, and therefore they are escape from infection by $B$. bassiana. The position of penetration has been described in Jaramillo et al. (2009) and Alba-Alejandre et al. (2018). At the position 1-2 the CBB is still outside-at the seed (endosperm) surface, whereas at the position 3-4 the CBB has already bored into the endosperm and forming gallery. When female has reproduced, the position of penetration has already deep inside the endosperm (position 3-4). We used mature green-yellow damaged coffee berries, and as such the CBB must be already inside the endosperm, therefore $B$. bassiana conidia sprayed upon the coffee berry surface would have less chance to reach the larvae which located inside the gallery in endoserm. It has been suggested by researchers that field application of insecticide in field should be done when the CBB is still in the surface of seed or before forming gallery and damaging endosperm to get good result (Baker et al., 2002). Similarly, it also desirable that application of any entomopathogen fungus also at the same penetration position of the beetle.

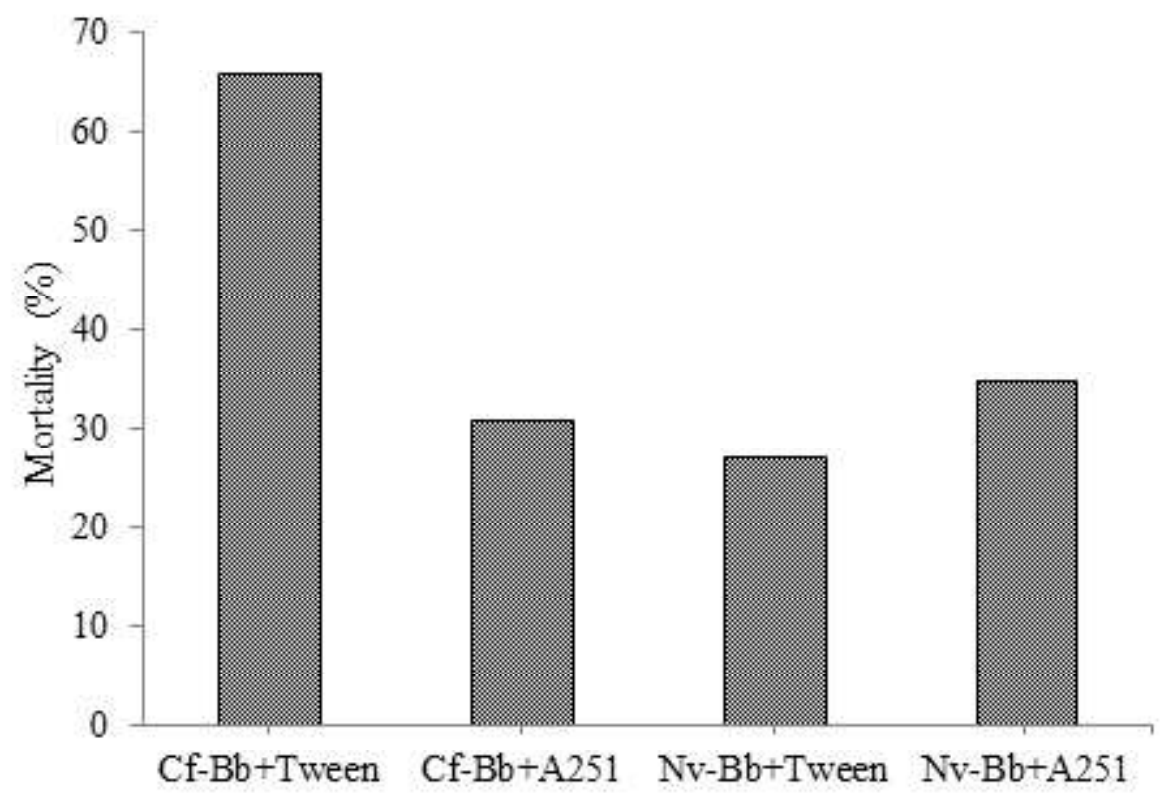

Figure 2. Percentages of CBB mortality inside damaged coffee berries sprayed with B. bassiana isolated from death insects; observation was done at day 9 after treatment.

Table 2. Means percentages of CBB mortality inside damage coffee berries 9 days after treated with $B$. bassiana at different conidia concentrations ${ }^{1)}$

\begin{tabular}{|c|c|c|c|c|}
\hline \multirow{2}{*}{\multicolumn{2}{|c|}{$\begin{array}{l}\text { Conidia concentration } \\
(\text { conidia } / \mathrm{mL})\end{array}$}} & \multicolumn{3}{|c|}{ Mortality $(\%)^{2)}$} \\
\hline & & Pupae & Adult & Pooled pupae + adult \\
\hline \multirow{4}{*}{ Trial 1} & $10^{6}$ & $13.03 \pm 19.73$ & $23.30 \pm 15.38$ & $21.36 \pm 18.21$ \\
\hline & $10^{7}$ & $24.72+21.70$ & $29.03+11.19$ & $26.43+18.93$ \\
\hline & $10^{8}$ & $35.71 \pm 35.91$ & $39.17 \pm 12.37$ & $37.11+26.07$ \\
\hline & $10^{9}$ & $69.44 \pm 15.67$ & $37.62 \pm 4.81$ & $45.06 \pm 16.43$ \\
\hline \multirow{4}{*}{ Trial 2} & $10^{6}$ & $11.11 \pm 9.623 \mathrm{a}$ & $14.25 \pm 3.418$ & $13.95 \pm 4.177 \mathrm{a}$ \\
\hline & $10^{7}$ & $17.97 \pm 7.988 \mathrm{ab}$ & $13.95 \pm 9.572$ & $15.74 \pm 3.532 \mathrm{ab}$ \\
\hline & $10^{8}$ & $27.43 \pm 8.110 \mathrm{ab}$ & $14.81 \pm 6.516$ & $16.97 \pm 7.711 \mathrm{ab}$ \\
\hline & $10^{9}$ & $25.51 \pm 7.588 \mathrm{~b}$ & $24.40 \pm 3.903$ & $23.79 \pm 3.021 \mathrm{~b}$ \\
\hline
\end{tabular}

1) All data are means \pm standard of deviation; data of control are not included in ANOVA; ${ }^{2}$ Means followed by the same later in the same column do not differ significantly (LSD; $\alpha=0.05$ ). 
Higher variability within concentrations in the first than that of the second test (indicated by the standard of deviation followed the means), lead to different results of analysis of variance, being significant only in the second but not in the first trial for pupae and pooled pupae + adult (Table 2), even though all corresponding means were almost twice higher in the first than in the second test. It is also apparent that the mean : variance ratio of the highest conidia concentration $\left(10^{9}\right)$ of both trial possess lower standard of deviation, indicated that the data are less variable, therefore we conclude that at low conidia concentration the results tend to be more variable or less reliable. The differences of the means of CBB mortality between the two tests were all significant, for pooled data across all concentrations, pupae, adult and pooled pupae and adult (two sample test $\mathrm{t}=2.32, \mathrm{df}=22, \mathrm{P}=0.0301$ for adult $\mathrm{t}=2.03, \mathrm{t}=0.051$ for pupae and $\mathrm{t}=2.5, \mathrm{P}=0.0202$ for pooled pupae + adult). We do not have rational argument for these differences. It might be the result of different conidia quality (e.g. viability) as a result of different mass production, and if so, it should be considered thoroughly in quality control of future mass production. The viability of conidia was examined only in the first mass production for the first trial, which was above $90 \%$, but was not repeated for the second trial. The variability of the results may be due to many factors that affected the experiments; some that were relevant to our study may be included the quality of conidia, the spray equipment used, temperature and humidity, and the timing of spray (Rosa et al., 2000). Mascarin et al. (2016) recommended the use of liquid based fermentation rather than solid base mass production to obtain more effective, robust and stable efficacy. In our experiments we use solid corn base media. The use of mature coffee berries in our experiments might also contribute to the variability of CBB mortality of our experiments. It might be different if we use green less mature coffee berries, which the position of CBB is still outside the endosperm. However, considering the un-distinct blooming/fruiting season of coffee in the Bengkulu, for future laboratory assay using damaged coffee berry, may be better that all position of CBB (1-2 and 3-4) are considered, but at separate tests or as treatment factors.

Results of conidia concentration tests were lower than that of pathogenicity test and it show closer reflection to real field application when this fungus isolate going to be used for controlling CBB population and/or damage upon coffee berry they incurred, inasmuch there will be some environmental factors that might be reduce further efficacy of the fungus.

We do not have comparison with other researcher's in the same method as we did, spraying damaged berries. However, results from field experiment reported by Rosa et al. (2000) might indicate that local isolate we used is indeed promising. They reported that the fungal infection on CBB after application of several isolate of $B$. bassiana at $10 \% / \mathrm{mL}$ upon coffee trees varied between isolates and altitude; the highest was $40.6 \%$ for the best isolate at 880 m.a.s.l., decreased little bit at 1100 m.a.s.l. and decreased much at 450 m.a.s.l. They also suggested that, in order to maintain and increase the efficacy of fungus in field condition, repeated applications were needed. Other study by Benavides $e t$ al. (2012) recorded the number of surviving egg, larvae, pupae and adult, which revealed that spraying artificially infested coffee berries in the soil surface with isolate mixture of $B$. bassiana caused significant reduction in new infestation of CBB on coffee barriers in tree by $15-55 \%$. Number of egg, and larvae was significantly much lower in treated plot with $B$. bassiana single or mixture isolates than that of control.

Our results showed that evaluation of small number of isolates can be performed by using spraying methods, where tested materials were applied upon damaged coffee berries with comparably good results. Spraying method upon damaged coffee berries is closer to real field condition.

\section{CONCLUSION}

B. bassiana proved to be more effective in causing mortality of CBB than $M$. anisopliae in the laboratory test using direct spraying of conidia upon CBB. Beetle mortality was 76.7 and $80.0 \%$ for $B$. basiana, and 60.3 and $60 \%$ for $M$. anysopliae treatments. In subsequence tests by spraying conidia upon damaged green-yellow mature coffee berries, $B$. bassiana caused much lower mortality to CBB pupae and imago. Application of higher concentration upon damaged coffee berry resulted higher mortality, but data were not consistent between first and second trials. Therefore, it must be considered in the future that mass production of the fungus must always be accompanied with viability evaluation and germination tests to assure the quality of conidia produced. Spraying method may be considered as an alternative, especially for pathogenicity test of small number isolates. 


\section{REFERENCES}

Alba-Alejandre I, Alba-Tercedor J, \& Vega FE. 2018. Observing the devastating coffee berry borer (Hypothenemus hampei) inside the coffee berry using microcomputed tomography. Sci. Rep. 8(17033): 1-9.

Aristizabal LF, Lara O, \& Arthurs SP. 2012. Implementing an integrated pest management program for coffee berry borer in a specialty coffee plantation in Colombia. J. Integ. Pest Mngmt. 3(1): G1-G5.

Baker PS, Jackson JAF, \& Murphy ST. 2002. Natural Enemies, Natural Allies: how scientists and coffee farmers forged new partnershipsin the war against pests and low prices. CABI commodities, Colombia.

Balakrishnan MM \& Naik PR. 2014. Infectivity of ten Metarhizium anisopliae isolates to the coffee berry borer Hypothenemus hampei (Coleoptera: Curculionidae). J. Entomol. Zool. Stud. 2(5): 246-249.

Belay YC \& Tenkegna TA. 2017. Bioassay and pilot mass production of entomopathogenic fungus, Beauveria bassiana for the control of coffee berry borer (Hypothenemus hampei: Scolytidae), Ferrari. J. Appl. Biosci. 117: 11669-11683.

Benavides P, Góngora C, \& Bustillo A. 2012. IPM program to control coffee berry borer Hypothenemus hampei, with emphasis on highly pathogenic mixed strains of Beauveria bassiana, to overcome insecticide resistance in Colombia. In: Perveen FK (Ed.). Insecticide-Advances in Intergrated Pest Management. pp. 511-540. Intech Open Access Publisher.

Brun LO \& Suckling DM. 1992. Field selection for endosulfan resistance in coffee berry borer (Coleoptera: Scolytidae) in New Caledonia. $J$. Econ. Entomol. 85(2): 325-334.

Brun LO, Marcillaud C, Gaudichon V, \& Suckling DM. 1989. Endosulfan resistance in Hypothenemus hampei (Coleoptera: Scolytidae) in New Caledonia. J. Econ. Entomol. 82(5): 1311-1316.
Brun LO, Suckling DM, Roush RT, Gaudichon V, Pheisler H, \& Robertson JL. 1995. Genetics of endosulfan resistance in Hypothenemus hampei (Coleoptera: Scolytidae): implications for mode of sex determination. J. Econ. Entomol. 88(3): $470-474$.

Brun LO, Stuart J, Gaudichon V, Aronstein K, \& FrenchConstant RH. 1995. Functional haplodiploidy: a mechanism for the spread of insecticide resistance in an important international insect pest. Proc. Natl. Acad. Sci. USA. 92(21): 9861-9865.

Celestino FN, Pratissoli D, Machado LC, Junior HGJDS, de Queiroz VT, \& Mardgan L. 2016. Control of coffee berry borer, Hypothenemus hampei (Ferrari) (Coleoptera: Curculionidae: Scolytinae) with botanical insecticides and mineral oils. Acta Sci. Agron. 38(1): 1-8.

Damon A. 2000. A review of the biology and control of the coffee berry borer, Hypothenemus hampei (Coleoptera: Scolytidae). Bull. Entomol. Res. 90(6): 453-465.

Dembilio O, Quesada-Moraga E, Santiago-Alvarez C, \& Jacas JA. 2010. Potential of an indigenous strain of the entomopathogenic fungus Beauveria bassiana as a biological control agent against the Red Palm Weevil, Rhynchophorus ferrugineus. J. Invertebr. Pathol. 104(3): 214-221.

Dufour BP \& Frerot B. 2008. Optimization of coffee berry borer, Hypothenemus hampei Ferrari (Col., Scolytidae), mass trapping with an attractant mixture. J. Appl. Entomol. 132(7): 591-600.

Feng MG, Poprawski TJ, \& Khachatourians GG. 1994. Production, formulation and application of the entomopathogenic fungus Beauveria bassiana for insect control: current status. Biocontrol Sci. Tech. 4(1): 3-34.

Infante F. 2018. Pest management strategies against the coffee berry borer (Coleoptera: Curculionidae: Scolytinae). J. Agric. Food Chem. 66(21): 52755280 .

Jaramillo J, Borgemeister C, \& Setamou M. 2006. Field superparasitism by Phymastichus coffea, parasitoid of adult coffee berry borer Hypothenemus hampei. Entomol. Exp. Appl. 119(3): 231-237. 
Jaramillo J, Chabi-Olaye A, Poehling HM, Kamonjo C, \& Borgemeister C. 2009. Development of an improved laboratory production technique for the coffee berry borer Hypothenemus hampei, using fresh coffee berries. Entomol. Exp. Appl. 130(3): 275-281.

Mascarin GM \& Jaronski ST. 2016. The production and uses of Beauveria bassiana as a microbial insecticide. World J. Microbiol. Biotechnol. 32(11): 177.

Patocka J. 2016. Bioactive metabolites of entomopathogenic fungi Beauveria bassiana. Mil. Med. Sci. Lett. 85(2): 80-88.

Posada FJ \& Vega FE. 2005. A new method to evaluate the biocontrol potential of single spore isolates of fungal entomopathogens. J. Insect Sci. 5(1): 110 .

Pérez J, Infante F, Poinar G, Castillo A, \& Vega FE. 2015. Natural parasitism of Metaparasitylenchus hypothenemi (Tylenchida: Allantonematidae) on the coffee berry borer in Chiapas, Mexico. Biocontrol Sci. Tech. 25(5): 608-612.

Perez-Lachaud G, Hardy ICW, \& Lachaud JP. 2002. Insect gladiators: competitive interactions between three species of bethylid wasps attacking the coffee berry borer, Hypothenemus hampei (Coleoptera: Scolytidae). Biol. Control. 25(3): 231-238.

Rosa WDL, Alatorre R, Barrera JF, \& Toriello C. 2000. Effect of Beauveria bassiana and Metarhizium anisopliae (Deuteromycetes) upon the coffee berry borer (Coleoptera: Scolytidae) under field conditions. J. Econ. Entomol. 93(5): 1409-1414.

Rosa WDL, Alatorre R, Trujillo J, \& Barrera JF. 1997. Virulence of Beauveria bassiana (Deuteromycetes) strains against the coffee berry borer (Coleoptera: Scolytidae). J. Econ. Entomol. 90(6): 1534-1538.
Sitanggang S, Sitepu SF, \& Lubis L. 2017. Survei serangan hama penggerek buah kopi (Hypothenemus hampei Ferr.) berdasarkan faktor kultur teknis di Kabupaten Tapanuli Utara. J. Agroekoteknologi. 5(4): 816-823.

Sparks TC \& Nauen R. 2014. IRAC: mode of action classification and insecticide resistance management. Pestic. Biochem. Physiol. 121: $122-128$.

Vega FE. 2004. Coffee berry borer, Hypothenemus hampei (Ferrari) (Coleoptera: Curculionidae: Scolytinae). In: Capinera JL (Ed.). Encyclopedia of Entomology. pp. 575-576. Springer, Dordrecht.

Vega FE, Infante F, Johnson AJ. 2015. The genus Hypothenemus, with emphasis on $H$. hampei, the coffee berry borer. In: Vega FE \& Hofstetter W (Eds.). Bark Beetles: Biology and Ecology of Native and Invasive Species. pp. 427-494. Academic Press, California.

Wiryadiputra S, Cilas C, \& Morin JP. 2008. Effectiveness of brocap trap in controlling coffee berry borer (Hypothenemus hampei (Ferr.)) in Indonesia. Proceedings of the 22nd International Conference of Coffee Science. pp.1405-1408. Association for Science and Information on Coffee (ASIC), Campinas, Brazil.

Wiryadiputra S. 2012. Effectiveness cyantraniliprole against coffee berry borer (Hypothenemus hampei) on arabica coffee. Pelita Perkebunan 28(2): 100-110. 